\title{
Introducción: Hibridismo y Poesía en el Siglo de Oro
}

\author{
Jesús Ponce Cárdenas \\ Universidad Complutense de Madrid \\ jmponce@ucm.es
}

La consolidación de la teoría de los géneros literarios en la Europa de la Edad Moderna constituyó, sin duda, una de las principales aportaciones del Humanismo italiano. Durante las décadas centrales del Quinientos, la interpretación de la Poética del Estagirita y de la horaciana Epistula ad Pisones sirvió para esclarecer la codificación de los antiguos genera, al tiempo que asentaba los cimientos para plantear un sistema comprensivo de clasificación que fuera más allá de la epopeya y la tragedia. ${ }^{1}$ En aquellos tiempos de fervor taxonómico brillaron eruditos de la talla de Robortello (Explicationes in librum Aristotelis qui inscribitur De Poetica, 1548), Trissino (Poetica, h. 1549), Minturno (Arte Poetica, 1564) o Torquato Tasso (Discorsi dell'arte poetica, h. 1566). Ahora bien, en el panteón de tratadistas ilustres que abordaron tal materia merecen una mención especial un humanista y una obra de singular calado: Giulio Cesare Scaligero y sus Poetices libri septem (1561).

En aquel volumen destinado a tener un influjo duradero, el conocido poeta doctus y notorio polemista abordaba el estudio de los géneros tanto en el libro I o Historicus (caps. 3-12 y 44-46) como en el libro tercero o Idea (caps. 95-101 y 123-125). El plantel genérico que emergía de aquellas páginas desplegaba ante los interesados en las litterae humaniores una variedad apabullante, ya que allí se diferenciaban categorías de todo tipo: poemata heroica, satyra, pastoralia, sylva, epithalamium, genethliacum, soteria, propempticon, epibaterion, apobaterion, pa-

1. Javitch (1991 y 1998). Para el ámbito hispánico, véase Rivers (1992). 
negyricon, laus, hymni, epitaphium, epicedium, monodia, threni, neniae, consolatio, elegia, epigramma. Scaligero planteaba en cada uno de los apartados una interesante presentación de cada espécimen, atendiendo a una suerte de esquema: definición del género, materia habitual de ese tipo de composiciones, repertorio de los lugares comunes más apropiados para el genus, catálogo de autores antiguos que pueden servir como modelos aptos para la imitación. Atendiendo a tal presentación, un escritor neófito que deseara componer sus versos al modo de los vates antiguos podía emplear como guía esa suerte de plantilla, en la que se evidenciaba cómo cada género tiene una estructura característica, un tema principal, una serie de tópicos que le son propios, un tono que lo caracteriza y - desde el punto de vista de la imitatio - un conjunto de modelos griegos y latinos que ofrecen posibles patrones de seguimiento.

Toda vez que el doble principio rector de la creación poética era la imitación y la emulación de los mejores dechados, la determinación del género resultaba crucial en varios aspectos. Sobre ese particular Rodrigo Cacho, en una reciente monografía, subrayaba cómo

El estudio de los géneros cumple necesariamente una tarea muy importante dentro de la crítica literaria sobre el Renacimiento y el Barroco, [ya que] a través de los géneros los escritores del Siglo de Oro aprendían a componer, desarrollaban su identidad creadora, diversificaban sus voces e intentaban construirse un propio espacio, un centro en el que perdurar y ser parte de la gran tradición del canon occidental (Cacho 2013: 7). ${ }^{2}$

Las citadas líneas del investigador cantabrigense evidencian de algún modo que la clasificación de textos poéticos mediante el casillero de los géneros resulta útil y necesaria, ya que permite catalogar gran número de piezas y poner orden en un panorama creativo muy rico, respetando siempre los parámetros estéticos del momento. ${ }^{3}$ Con todo, dicha tarea no estará exenta de dificultades, ya que algunas obras son especialmente refractarias a la clasificación, puesto que se mueven dentro de unos contornos inciertos y participan de los rasgos de una multiplicidad de líneas genéricas. En ese punto conviene recordar el concepto de hibridación, que el Diccionario de la Real Academia define como la "fusión de dos células de distinta estirpe para dar lugar a otra de características mixtas". Al igual que sucede en el campo de la biología, el estudio de la Poesía del Siglo de Oro necesita dilucidar paulatinamente cómo se verifican los procesos de "fusión" de dos o más géneros para dar lugar a una obra "de características mixtas".

2. Sobre las implicaciones de la imitatio y los géneros puede verse asimismo Ponce Cárdenas (2016: 97-103).

3. Justo es apuntar el gran impulso que cobró el estudio de los géneros de la poesía áurea gracias al esfuerzo colectivo del grupo PASO, que a lo largo de varias décadas ha dedicado diferentes volúmenes a la silva, la oda, la elegía, la epístola y la égloga. 
En este monográfico no nos interesan aquellos textos áureos que se atienen con escrupuloso detalle a los patrones de un género dado, sino el tipo de composiciones híbridas que presentan perfiles huidizos y que resultan, por ello, difíciles de encajar en un molde claro. Más allá de las muestras iniciales de fusión genérica del Quinientos (con la Égloga segunda de Garcilaso en destacadísimo primer plano), la literatura del siglo XvII ofrece una serie de ejemplos de composiciones en las que se entremezclan dos o más modalidades poéticas mediante la práctica de la contaminatio: la canción petrarquista y el kateunastikòs lógos (o 'discurso del lecho nupcial'), el panegírico y la égloga, la silva y el epinicio, la poesía descriptiva de espacios aristocráticos y el basilikòs lógos (o 'discurso regio')... Tales procesos de hibridación afectan a menudo a poemas de primer rango, en los que no solo se fusionan varios géneros sino que también se da acogida en los versos a diferentes estilos.

Haciendo un rápido balance, podría afirmarse que la atención que algunos estudios han dedicado a las prácticas de hibridación literaria durante la Edad Moderna ha arrojado luz sobre algunos casos notables, sobre todo en el ámbito de la prosa y el teatro. Baste aducir aquí tres testimonios relevantes: el monográfico coordinado por Soledad Arredondo sobre "Géneros híbridos y libros mixtos" (2013), el artículo de I. D. Arellano sobre la hibridación en la novela bizantina (2017) y el monográfico "En los márgenes del canon: hibridismo literario y cultura áurea" (2021), dirigido por Inmaculada Osuna y Elena Martínez. Por otro lado, si se dirige la atención a otros períodos, la cuestión del hibridismo también ha suscitado el interés de los especialistas en las letras contemporáneas, tal como prueba la colectánea en torno al "Mash-up. Forme e valenze dell'ibridazione nella creazione letteraria" coordinada por Pietro Taravacci en la Universidad de Trento (2016). El presente monográfico aspira a cubrir una ausencia importante en el ámbito de los estudios sobre poesía áurea, ya que si bien hasta la fecha se han publicado trabajos de indudable interés sobre un fenómeno creativo de singular valor, sin embargo, no se ha dedicado en exclusiva un conjunto de artículos en torno a la hibridación o contaminatio en un monográfico de una revista especializada.

La práctica de la fusión de géneros no puede considerarse un fenómeno aislado en la poesía española del período, sino que debe ponerse en relación con estrategias afines empleadas por los vates neolatinos y los poetas italianos desde el Quattrocento. Algunos nombres mayores de la lírica redactada en latín humanístico (baste recordar la colección de diez pompae que integran la Lepidina de Pontano o el conjunto de las Siluae de Poliziano) así como varios poemas de relieve en lengua vernácula (citaremos tan solo las Stanze per la giostra di Giuliano di Medici del mismo Poliziano o el ambicioso poema de Giovan Vincenzo Imperiale dedicado a Lo stato rustico) pudieron espolear a los escritores del Siglo de Oro a recorrer las sendas de la contaminación de géneros y modelos.

La trascendencia de la obra maestra de Góngora como ejemplo máximo de contaminatio en la literatura barroca justifica por sí sola la inclusión de tres artí- 
culos que sondean el funcionamiento de algunos mecanismos de la hibridación en las Soledades. En primer lugar, Jesús Ponce Cárdenas aborda el estudio de la comparación de la novia aldeana con una rosa a punto de eclosionar (Soledad primera, vv. 722-731), analizando en detalle los diferentes hipotextos que vertebran el pasaje. La articulación de una figura de dicción de rancio abolengo y próspera fortuna remitía sin ambages a los lectores de la época a la esfera sublime del paragone épico (Homero, Estacio, Claudiano, Tasso). Con todo, tal como pone de manifiesto el ensayo, la naturaleza elegante y estilizada del término de comparación en realidad se inspira en el stile venusto de un soneto de elogio cortesano compuesto por Torquato Tasso en honor de la duquesa de Urbino (Negli anni acerbi tuoi purpurea rosa).

El trabajo de Daniel Mateo Benito se centra en un aspecto llamativo de la sección epitalámica de la Soledad primera: la presencia de Níobe como arquetipo de fecundidad femenina y el ejemplar castigo que sufrió por su jactancia. Desde el punto de vista de la articulación de la figura mítica, Góngora pudo tener en cuenta la aparición de la prolífica heroína griega en numerosos epigramas, desde la Antigüedad hasta el Siglo de Oro. El artículo revela asimismo un aspecto funcional interesante en la inclusión de la hija de Tántalo y su luctuosa historia en el poema, puesto que cabe considerarla a todos los efectos una muestra singular de exemplum a contrario, por cuanto se refiere a los riesgos que entrańa la soberbia.

El estudio de Juan Matas Caballero pone el foco en un detalle altamente sugestivo de la Soledad segunda: el símil de la burla hidráulica (vv. 222-229). La presencia de un elemento suntuario propio de los jardines palaciegos del Siglo de Oro permite conectar el pasaje gongorino con la tradición de las poesie di ville o poemas descriptivos de villas, palacios y jardines. Resultan así de gran interés los paralelos que plantea este fragmento con unos versos de Lo stato rustico de Imperiale y con una octava de Lope de Vega, perteneciente al encomio cortesano de la famosa Descripción de Abadia, jardin del duque de Alba.

Junto a Góngora, otro gran adalid de la mezcla de géneros en la literatura del siglo Xvir fue sin duda Lope de Vega, que llevó la contaminatio a cimas insospechadas en varios lugares de su obra. El artículo de J. Ignacio Díez Fernández fija su atención en la escritura epistolar del Fénix para reflexionar sobre los perfiles del hibridismo, la materia amatoria y la autodefensa en un díptico de composiciones tan enigmático como la Epistola de Amarilis y la respuesta a la misma del prolífico autor madrileño.

De la mano de Isabel Colón Calderón pasamos de los grandes nombres de la literatura barroca al entorno reservado y umbrío propio de las numerosas figuras secundarias de la poesía del siglo XvII. La investigadora complutense acomete el examen de una curiosa composición, no muy conocida hoy, del vallisoletano Gabriel de Henao: las octavas descriptivo-encomiásticas dedicadas al palomar del conde de Monterrey.

El monográfico se cierra con un artículo de Alberto Fadón Duarte consagrado a la composición más ambiciosa del escritor y diplomático Bernardino de 
Rebolledo: las Selvas dánicas. En la segunda parte de las mismas, el encomiasta se centra en la evocación del palacio danés de Hirscholme y da cuenta de los parajes naturales que lo rodean, los exquisitos jardines que lo circundan y las pinturas que lo adornan. El artículo pone de relieve cómo el conde de Rebolledo siguió de cerca el modelo estilístico de Góngora para cantar en estilo sublime la elegancia de una residencia real que hoy ya no existe.

Estas seis calas en el estudio de algunos procesos de hibridación reconocibles en la poesía áurea constituyen el resultado de un primer trabajo en equipo. En tanto fruto de un esfuerzo común destinado a dilucidar un fenómeno complejo en la creación lírica de la Edad Moderna, el presente conjunto de artículos se inserta en una de las líneas del Proyecto "Hibridismo y Elogio en la España Áurea” (HELEA PGC2018-095206-B-I00), financiado por el Ministerio de Ciencia, Investigación y Universidades y el Fondo Europeo de Desarrollo Regional FEDER. 


\section{Bibliografía}

Arellano Torres, Ignacio D., "Hibridación en el género bizantino: los viajes en Los trabajos de Persiles y Sigismunda", en Viajeros, crónicas de Indias y épica colonial, ed. Mariela Insúa y Jesús Menéndez Peláez, Nueva York, IDEA, 2017, pp. 227-242.

Arredondo, Soledad (dir.), Géneros híbridos y libros mixtos en el Siglo de Oro, número monográfico de Mélanges de la Casa de Velázquez, XLIII, 2 (2013).

Сасно, Rodrigo, "Introducción: Géneros, centros, periferias", en Los géneros poéticos del Siglo de Oro. Centros y periferias, ed. Rodrigo Cacho y Anne Holloway, Londres, Tamesis, 2013, pp. 1-9.

Javitch, Daniel, "La politica dei generi letterari nel tardo Cinquecento", Studi italiani, III, 2 (1991), pp. 5-22.

-, "The Emergence of Poetic Genre Theory in the Sixteenth Century", Modern Language Quarterly, LIX, 2 (1998), pp. 139-169.

Osuna, Inmaculada, y Martínez Carro, Elena (coord.), En los márgenes del canon. Hibridismo literario y cultura áurea, número monográfico de Hipogrifo. Revista de Literatura y Cultura del Siglo de Oro, IX, 1 (2021).

Ponce Cárdenas, Jesús, La imitación áurea. Cervantes, Quevedo, Góngora, París, Éditions Hispaniques, 2016.

Rivers, Elias L., "Géneros poéticos en el Siglo de Oro", Nueva Revista de Filología Hispánica, LX, 1 (1992), pp. 251-264.

Taravacci, Pietro (dir.), Mash-up. Forme e valenze dell'ibridazione nella creazione letteraria, número monográfico de Ticontre. Teoria, testo, traduzione, núm. 5 (2016), en línea, <http://www.ticontre.org/ojs/index.php/t3/issue/ view/7>. 